\title{
Niveles de vitamina D en médicos; ¿son los anestesiólogos el único grupo de riesgo?
}

\author{
Ojeda D. ${ }^{1}$, Cabezón M. ${ }^{2}$, Agurto M. ${ }^{1}$, Oviedo S. ${ }^{1}$, Vega C. ${ }^{1}$, Daza X. ${ }^{1}$, Demetrio B. ${ }^{1}$, Carrasco C. ${ }^{1}$, Cisternas P. ${ }^{1}$ \\ 1 Clínica Dávila, Santiago, Chile. \\ 2 Universidad de Los Andes, Santiago, Chile.
}

Dado que la exposición solar es la principal fuente de 25-hidroxi-vitamina D, se ha sindicado a los anestesiólogos como un grupo de riesgo para su déficit. En general la labor médica se desarrolla en interiores, lo que agregado al exceso de trabajo y sedentarismo, condicionan el que los galenos en general no se expongan al sol.

Se diseñó un estudio observacional de tipo corte transversal para investigar los factores determinantes de los niveles de vitamina $\mathrm{D}$ en médicos. Se incluyeron a anestesiólogos y otros especialistas cuyo trabajo no se desarrollara en pabellones quirúrgicos. Se aplicó una encuesta que incluía, horas de trabajo, dieta, coloración de la piel, uso de bloqueador solar y actividades al aire libre. Se midieron niveles de vitamina D y Parathormona.

Por medio de regresión lineal múltiple se detectó que no había diferencias en los niveles de vitamina $\mathrm{D}$ entre anestesiólogos y no anestesiólogos: $\beta=1,1[0,9-1,4] ; p=0,286$, la presencia de un índice de masa corporal elevado era un factor de riesgo: $\beta=0,96[0,93-0,99] ; p=0,025$, (Figura 1) y el único factor protector fue la ingesta de un suplemento de vitamina $D: \beta=1,56[1,3-1,9] ; p=0,000$, (Figura 2).

En conclusión, el déficit de vitamina D afectaba a los médicos en general, independientemente de su especialidad. Los niveles de vitamina D disminuían frente al incremento del índice de masa corporal y la única manera de mantenerlos normales era la utilización de un suplemento.

https://doi.org/10.25237/congresoclasa2019.07 